\title{
S. cerevisiae Outer and Inner Membranes are Compromised upon Benzyl Alcohol Treatment
}

\author{
Bengü Ergüden
}

\author{
Department of Bioengineering, Gebze Technical University, Kocaeli, Turkey
}

\begin{abstract}
Although there are innovations in the treatment of diseases caused by fungi and medicines with multiple targets have been developed, the search for a drug with a broad spectrum and without any side effects continues to date. It is generally accepted that determining the cellular target responsible for the toxic effect opens up new possibilities for the development of new drugs. Especially the effects of antifungal agents on the surface components of the fungal cell, on cell wall synthesis and the identification of the target site are crucial in antifungal drug development. Thus studies on the fungal cell membranes in connection with the antifungal agents, aim to develop new strategies for the therapy of fungal infections. Antifungal agents targeting fungal cell wall and cell membrane components have increased in importance in clinical studies. In this study, understanding the mechanism of action of benzyl alcohol, a known membrane fluidizer, and the determination of its cellular targets are aimed. We have shown that in the presence of sorbitol, the osmotic stabilizer, benzyl alcohol becomes less effective against yeast cell. Moreover, benzyl alcohol disrupts cell membrane, causing leakage of ions to the extracellular medium. Nuclear membrane is distorted upon treatment of yeast cells with benzyl alcohol. Thus, we conclude that both outer and inner yeast cell membranes are compromised by the action of benzyl alcohol.
\end{abstract}

Keywords: Benzyl alcohol, Cell wall, Cell membrane, Yeast, Antifungal activity.

\section{INTRODUCTION}

The fungal cell wall, located at the outermost part of the cell, is solid and flexible and is the interface between cell and surroundings. It is a versatile structure that enables the cell wall to control cell secretion and uptake in order to maintain intracellular osmotic balance, protect the cell from the environment, transform the nutrients taken into metabolizable form and maintain cell shape [1-3]. Considering the components that make up this structure, glucan $[\beta$ $(1,3)$-D-glucan, $\beta$-(1,6)-D-glucan], chitin and mannan proteins, are essential for the life cycle of the fungus. There are antifungal agents that inhibit the fungal cell wall by targeting glucan, chitin, and mannan proteins [4-8]. In consequence of the fungal cell wall becoming resistant to antifungal agents, the causes of this resistance have been investigated and new treatments have been developed [9-14].

The cell wall of yeast and different types of fungi is a solid structure that provides mechanical conservation and backing the inner osmotic pressure of the cell. The cell wall ensures the integrity of cell form in the cell's growth, division, and formation of a large number of cell types and is therefore highly flexible [2]. And besides, the cell wall has a dynamic structure that can comply with physiological and morphological changes, e.g. ion

"Address correspondence to this author at the Department of Bioengineering, Gebze Technical University, Gebze 41400, Kocaeli, Turkey;

Tel: 0090262 6053323; E-mail: b.sezen@gtu.edu.tr exchange and filtration, antigenic expression, etc. The fungal cell wall is mainly composed of polysaccharides and glycoproteins. To form the cell wall, fungal cells must either synthesize the wall components in the plasma membrane or transfer the components outside the cell and join them outside the cell. Cell wall components vary according to fungal species. The cell wall consists of mannoproteins, alpha-beta glucans and chitin, which are the three essential polysaccharides.

In this study, we set out to determine cellular target of benzyl alcohol, a known membrane fluidizer, on Saccharomyces cerevisiae cells [15]. For this purpose, we studied possible defects in the yeast cell wall, cell membrane and nuclear membrane structures upon treatment with benzyl alcohol. We believe that, these studies on the fungal cell membranes in connection with the antifungal agents, opens up new possibilities for the therapy of fungal infections.

\section{MATERIALS AND METHODS}

\section{Strain Constructions and Growth Conditions}

YPH499 (MATa ura3-52 lys2-801_amber ade2101_ochre trp1- $\Delta 63$ his3- $\Delta 200$ leu2- $\Delta 1$ ) [16] was used as the Saccharomyces cerevisiae strain in all experiments. Typically, cells were grown in yeast extract peptone glucose medium (YPD) at $25{ }^{\circ} \mathrm{C}$ and then precultured in YPD medium for $24 \mathrm{~h}$. $100 \mu \mathrm{L}$ of inoculum was added to $10 \mathrm{~mL}$ fresh YPD medium, and the main culture was grown until it had reached the early exponential phase. 


\section{Minimum Inhibitory Concentration (MIC) Measurement}

The minimum inhibitory concentration (MIC) measurement was performed in similar procedure with our previous study [15]. S. cerevisiae cells were cultured overnight at $25^{\circ} \mathrm{C}$ in YPD broth and were suspended in YPD to give a final density of $1 \times 10^{6}$ $\mathrm{CFU} / \mathrm{mL}$. Benzyl alcohol dissolved in dimethyl sulfoxide (DMSO) were prepared at different concentrations and put in 24-well microtiter plate. After that, S. cerevisiae cells were added to each well, separately. Suspension of yeast cells in the medium without benzyl alcohol and yeast cells in the medium with only DMSO were tested as controls. 24-well microtiter plates were incubated at $25^{\circ} \mathrm{C}$. The MIC was determined after $24 \mathrm{~h}$ according to the control fungal growth and further confirmed after 48 h. Viability of yeasts was deduced based on turbidity.

\section{Extracellular Conductivity Measurement}

The permeability of $S$. cerevisiae cell membranes is expressed in terms of their electric conductivity. After overnight incubation of yeast cells at $25^{\circ} \mathrm{C}$ in $20 \mathrm{~mL}$ of YPD, the cells were centrifuged at $3200 \mathrm{rpm}$ for $5 \mathrm{~min}$ and pellet was washed twice with sterilized $\mathrm{dH}_{2} \mathrm{O}$. The pellet was then resuspended in sterilized $\mathrm{dH}_{2} \mathrm{O}$. About $200 \mathrm{mg}$ wet weight of $S$. cerevisiae cells were used for each experiment. $5 \mathrm{mM}$ and $10 \mathrm{mM}$ of benzyl alcohol dissolved in DMSO were added to the above resuspended solution at zero point. Extracellular conductivity was recorded every 5 min with an AD 31 Waterproof EC/TDS tester (Adwa, HUNGARY). In order to assess whether treatment with benzyl alcohol caused statistically significant changes, analyses were performed on the slopes of the regression lines plotted using each data set [17]. The slope of extracellular conductivity regression line for $10 \mathrm{mM}$ of benzyl alcohol treated yeast cells is statistically significant from the slope derived from extracellular conductivity of untreated cells $(P, 0.05)$.

\section{Sorbitol Protection Assay}

To assess whether the cell wall is the target of active compounds, MIC values were determined by the standard procedure described above in the absence and presence of $0.8 \mathrm{M}$ sorbitol [18]. Plates were incubated at $25{ }^{\circ} \mathrm{C}$ and read after $48 \mathrm{hrs}$. MICs were defined as the lowest concentration of benzyl alcohol capable of visually inhibiting the fungal growth.

\section{Ergosterol Effect Assay}

To assess whether the benzyl alcohol bind to fungal membrane sterols, the MIC value was determined by the method described above in the absence or presence of various amounts $(0,50,100,150,200$ and $250 \mu \mathrm{g} / \mathrm{ml}$ ) of ergosterol [18]. The plates were incubated at $25{ }^{\circ} \mathrm{C}$ for 48 hours and analysed. This binding assay reflected the ability of the benzyl alcohol to bind to ergosterol.

\section{Fluorescence Microscopy}

Still images of non-fixed cells in growth medium were acquired at room temperature with a wide-field epifluorescence microscope (Axio Imager.A1; Carl Zeiss Microlmaging) equipped with 100x NA 1.45 oil immersion objective (Plan-Fluar; Carl Zeiss Microlmaging), a Cascade:1K camera (Photometrics) and Metamorph software (Universal Imaging). Photoshop (Adobe) was used to mount the images and to produce merged colour images. No manipulations other than contrast, brightness and colour balance adjustments were used.

\section{RESULTS}

\section{Fungal Cell Wall is Compromised by the Action of Benzyl Alcohol}

We have previously reported antifungal activities of various terpenoids as well as benzyl alcohol against yeast Saccharomyces cerevisiae [15]. Benzyl alcohol was shown to be effective against yeast cells (Table 1). In search for possible targets of the benzyl alcohol, we first focused on the cell wall.

The fungal cell wall is a crucial barrier for morphogenesis and serves in protection of cells against environmental stresses, particularly external osmotic changes. Thus, disruption of the cell wall induced by antifungal agents is one of the main causes of fungal death $[19,20]$. Sorbitol is an osmotic stabilizer and the sorbitol protection assay was performed to unearth any effect of benzyl alcohol on the integrity of the fungal cell wall. Our results demonstrate that the benzyl alcohol MIC value increases in the presence of osmotic stabilizer sorbitol (Table 1), which suggests that the benzyl alcohol treatment compromises fungal cell wall.

Table 1: Antifungal Activity of Benzyl Alcohol in the Presence and Absence of Sorbitol

\begin{tabular}{|c|c|c|}
\hline & - Sorbitol & $\mathbf{+ 0 . 8} \mathbf{M}$ Sorbitol \\
\hline \hline MIC & $5.0-10.0 \mathrm{mM}$ & $>20 \mathrm{mM}$ \\
\hline
\end{tabular}


Benzyl alcohol was mixed with DMSO to increase solubility. DMSO level did not exceed $1 \%$ in all cases. MIC measurements were repeated three times.

\section{Cell Membrane Integrity is Disrupted by Benzyl Alcohol}

We have previously reported our results on the increase of extracellular conductivity of yeast cells upon treatment with benzyl alcohol [15]. In order to observe the immediate effect on the membrane integrity of yeast cells, we treated them with $5 \mathrm{mM}$ and $10 \mathrm{mM}$ of benzyl alcohol for $30 \mathrm{~min}$, and measured extracellular conductivity with $5 \mathrm{~min}$ intervals (Figure 1a) [15].

In order to show that the effect of $10 \mathrm{mM}$ benzyl alcohol treatment is statistically significant than the control, regression lines were plotted for each data set [17]. The formula for the regression line for the control (where no benzyl alcohol is added) was found to be $y=0,0976 x+1,2976$. The formulae for the benzyl alcohol treatments are as follows: $5 \mathrm{mM}$ benzyl alcohol $y=0,1524 x+1,4762$; and $10 \mathrm{mM}$ benzyl alcohol $y=0,3643 x+1,1071$. The slopes of the regression lines are shown on the bar graph (Figure 1b). We conclude from this data that $10 \mathrm{mM}$ benzyl alcohol caused disruption of cell membrane integrity and ion leakage from yeast cells statistically significant from the control cells.

\section{Benzyl Alcohol Act on Cell Membrane by Binding to Ergosterol}

The fungal cell membrane is a dynamic structure composed of a lipid bilayer where enzymes and transport proteins are embedded. Ergosterol, the lipid steroid of fungal cell membrane, functions as an important regulator of membrane fluidity. Therefore, ergosterol and enzymes of the ergosterol biosynthetic pathway are important targets of antifungals [21]. Possible role of ergosterol on the action of benzyl alcohol was studied by the ergosterol effect assay. In this assay, the efficiency of the antifungal agent was determined in the presence of added exogenous ergosterol. If the compound under consideration acts on fungal cell membrane via binding to the ergosterol, it will mostly bind to the exogenous ergosterol, and this will retard its binding to the membrane bound ergosterol; resulting in a decrease in its antifungal activity and a corresponding increase in its MIC value [18]. In our study, when exogenous ergosterol was added to the growth medium, MIC for benzyl alcohol increased by 2-4 fold (Figure 2), suggesting that the ergosterol binding is a crucial step for benzyl alcohol action on yeast cell membrane.

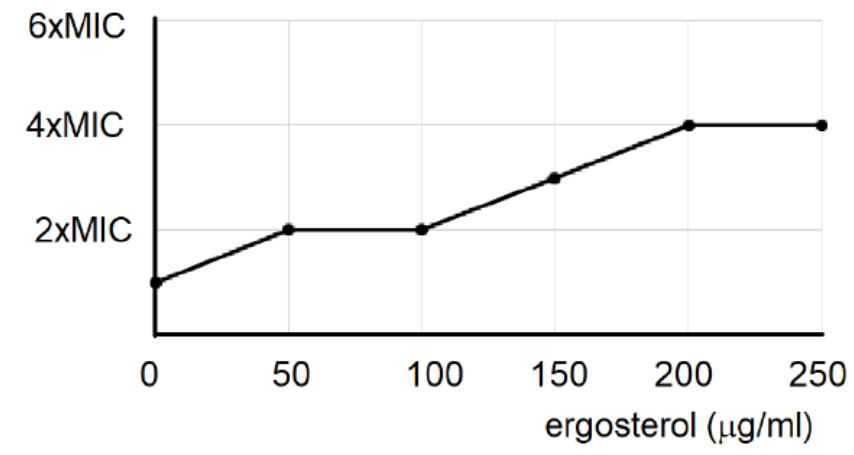

Figure 2: Effect of exogenous ergosterol on the MIC value of benzyl alcohol.

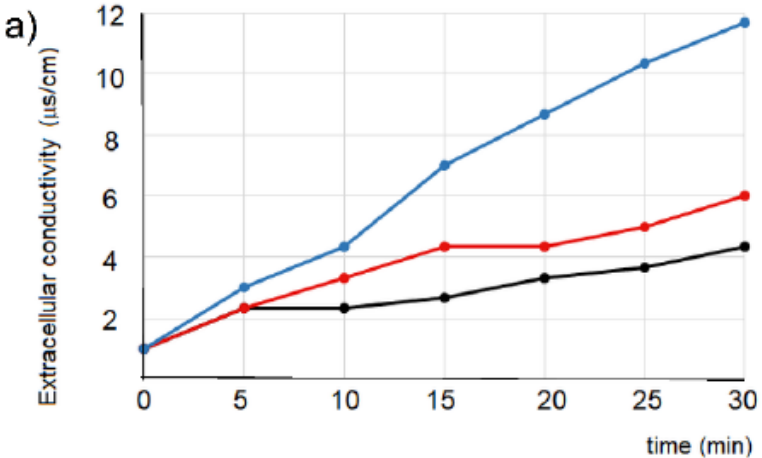

b)

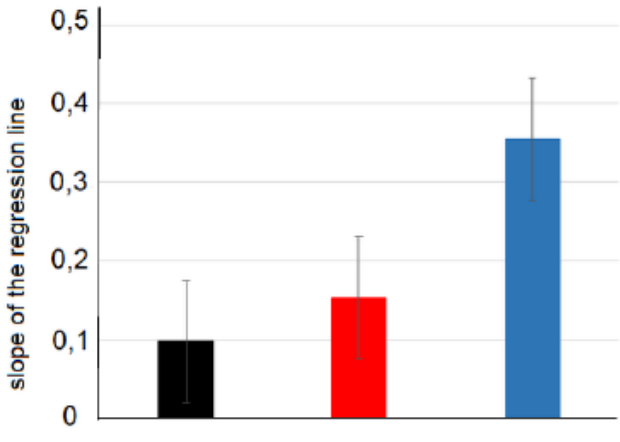

$\rightarrow$ control $\rightarrow 5 \mathrm{mM}$ benzyl alcohol $\rightarrow 10 \mathrm{mM}$ benzyl alcohol

Figure 1: a) Effect of benzyl alcohol on the extracellular conductivity of $S$. cerevisiae cells. Control corresponds to the measurements performed with no compound added. Point zero indicate the time of addition of the benzyl alcohol. The data represent the average of at least three independent experiments. b) The slopes of the regression lines of the extracellular conductivity measurements shown in (a). 
a)

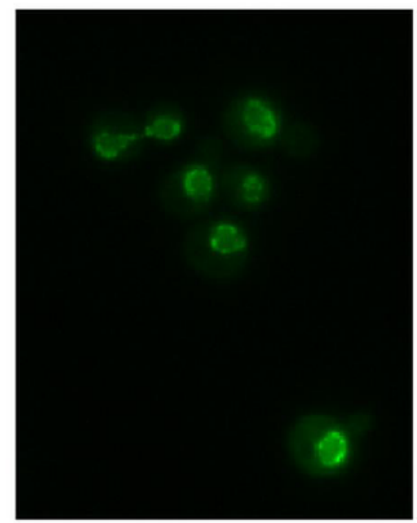

b)

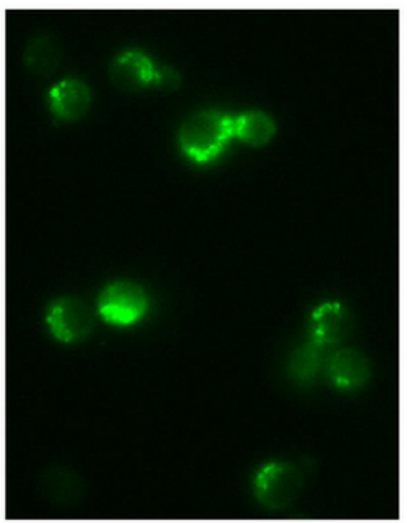

Figure 3: Nuclear envelope phenotype of benzyl alcohol treated cells. a) Yeast cells were transformed with pRS315-GFPNUP49 and analyzed by fluorescence microscopy. b) Yeast cells, transformed with pRS315-GFP-NUP49, were treated with 1\% benzyl alcohol for 15 min and analyzed by fluorescence microscopy.

\section{Nuclear Membrane is Distorted Benzyl Alcohol Treated Yeast Cells}

We also wanted to observe any effect of benzyl alcohol on the organelle membranes of yeast cells. Visualization of the nuclear membrane by means of labelling the Nup49 protein, a protein in the structure of nuclear pore complex that is embedded to the nuclear membrane, with GFP revealed that yeast cells had highly deformed nuclear membranes (Figure 3).

\section{DISCUSSION AND CONCLUSION}

We have previously shown benzyl alcohol to be active against $S$. cerevisiae cells [15]. In this study, we focused on the possible cellular targets of antifungal agent benzyl alcohol, a known membrane fluidizer. We have shown that presence of sorbitol in the extracellular medium decreases antifungal activity of benzyl alcohol. Sorbitol is an osmotic protectant and it is expected that the MIC of a compound that damages the cell wall will shift to a much higher value in the presence of this osmotic support. Thus our sorbitol protection assay result suggests that the yeast cell wall is affected by the action of benzyl alcohol (Table 1). Additionally, disruption of cell membrane integrity upon benzyl alcohol treatment was shown by the leakage of ions from cells demonstrated by the increase of extracellular conductivity (Figure 1 ). We have also shown that ergosterol binding is crucial for the action of benzyl alcohol on yeast cell membrane (Figure 2). Moreover, yeast nuclear membrane is morphologically distorted by the action of benzyl alcohol (Figure 3 ).

In summary, our study revealed that benzyl alcohol acts on yeast cells via multiple membranous targets; each having vital roles for the cell and thus perhaps contributing to the antifungal activity of benzyl alcohol. As a future goal, we aim to investigate the consequences of these inner and outer membrane distortions. Especially, any defects in the transport through the distorted nuclear membrane will be studied in detail.

\section{FUNDING}

No funding was received.

\section{REFERENCES}

[1] Free SJ. Fungal cell wall organization and biosynthesis. J of Bacteriol 1998; 180: 3735-3740. https://doi.org/10.1128/JB.180.15.3735-3740.1998

[2] Lipke PN, Ovalle R. Cell wall architecture in yeast: New structure, new challenges. Lett Appl Microbiol 2003; 37: 268269.

[3] Ruiz-Herrera J, Elorza MV, Valentin E, Sentandreu R Molecular organization of the cell wall of Candida albicans and its relation to pathogenicity. FEMS Yeast Res. 2006 6(1): 14-29. https://doi.org/10.1111/j.1567-1364.2005.00017.x

[4] Walker SS, Xu Y, Triantafyllou I, Waldman MF, Mendrick C, Brown $\mathrm{N}$, et al. Discovery of a novel class of orally active antifungal beta-1,3-D-glucan synthase inhibitors. Antimicrob Agents Chemother. 2011; 55(11): 5099-106. https://doi.org/10.1128/AAC.00432-11

[5] Kathiravan MK, Salake AB, Chothe AS, Dudhe PB, Watode RP, Mukta MS, Gadhwe S. The biology and chemistry of antifungal agents: A review. Bioorg Med Chem 2012; 20: 5680-5684

https://doi.org/10.1016/j.bmc.2012.04.045

[6] Pfaller MA, Messer SA, Motyl MR, Jones RN, Castanheira M. Activity of MK-3118, a new oral glucan synthase inhibitor, tested against Candida spp. by two international methods (CLSI and EUCAST). J Antimicrob Chemother. 2013; 68 858-63. https://doi.org/10.1093/jac/dks466

[7] Lepak AJ, Marchillo K, Andes DR. Pharmacodynamic target evaluation of a novel oral glucan synthase inhibitor, SCY-078 (MK-3118), using an in vivo murine invasive candidiasis model. Antimicrob Agents Chemother. 2015; 59: 1265-72. https://doi.org/10.1128/AAC.04445-14 
[8] Aderiye $\mathrm{BI}$, Oluwole OA. Antifungal agents that target fungal cell wall components: A review. Agri Biol Sci 2015; 1: 207212.

[9] McLellan CA, Whitesell L, King OD, Lancaster AK, Mazitschek R, Lindquist S. Inhibiting GPI anchor biosynthesis in fungi stresses the endoplasmic reticulum and enhances immunogenicity. ACS Chem Biol. 2012; 7(9): 1520-8. https://doi.org/10.1021/cb300235m

[10] Cortés JCG, Curto MA, Carvalho VSD, Pérez P, Ribas JC. The fungal cell wall as a target for the development of new antifungal therapies. Biotechnol Adv 2019; 37: 107352. https://doi.org/10.1016/j.biotechadv.2019.02.008

[11] Hasim S, Coleman JJ. Targeting the fungal cell wall: current therapies and implications for development of alternative antifungal agents. Future Med Chem 2019; 11: 871-875. https://doi.org/10.4155/fmc-2018-0465

[12] Liu W, Yuan L, Wang S. Recent progress in the discovery of antifungal agents targeting the cell wall. J Med Chem 2020; 63: $12429-12459$ https://doi.org/10.1021/acs.jmedchem.0c00748

[13] Ibe C, Walker LA, Gow N, Munro CA. Unlocking the therapeutic potential of the fungal cell wall: clinical implications and drug resistance. In: Prasad R, editor. Candida albicans: Cellular and Molecular Biology. United Kingdom: Springer International Publishing; 2017. p. 313-46. https://doi.org/10.1007/978-3-319-50409-4 16

[14] Ibe C, Munro CA. Fungal cell wall: An underexploited target for antifungal therapies. PLOS Pathogens 2021; 17: e1009470.

https://doi.org/10.1371/journal.ppat.1009470
[15] Konuk HB, Ergüden B. Phenolic $-\mathrm{OH}$ group is crucial for the antifungal activity of terpenoids via disruption of cell membrane integrity. Folia Microbiol 2020; 65: 775-783. https://doi.org/10.1007/s12223-020-00787-4

[16] Sikorski RS, Hieter P. A system of shuttle vectors and yeast host strains designed for efficient manipulation of DNA in Saccharomyces cerevisiae. Genetics 1989; 122: 9-27. https://doi.org/10.1093/genetics/122.1.19

[17] Andrade JM, and Estevez-Perez MG, Statistical comparison of the slopes of two regression lines: A tutorial. Analytica Chim Acta 2014; 838: 1-12. https://doi.org/10.1016/j.aca.2014.04.057

[18] Pereira FO, Mendes JM, Lima EO. Investigation on mechanism of antifungal activity of eugenol against Trichophyton rubrum. Medical Mycology 2013; 51: 507-513. https://doi.org/10.3109/13693786.2012.742966

[19] Sartoratto A, Machado ALM, Delarmelina C, Figueira GM Duarte MCT, Rehder VLG. Composition and antimicrobial activity of essential oils from aromatic plants used in Brazil. Braz J Microbiol 2004; 35: 275-280. https://doi.org/10.1590/S1517-83822004000300001

[20] Bowman S, Free SJ. The structure and synthesis of the fungal cell Wall. Bioassays 2006; 28: 799-808. https://doi.org/10.1002/bies.20441

[21] Martinez-Rossi NM, Peres NTA, Rossi A. Antifungal resistance mechanisms in dermatophytes. Mycopathologia 2008; 166: 369-383 https://doi.org/10.1007/s11046-008-9110-7

DOI: https://doi.org/10.15379/2410-1869.2021.08.02.03

(c) 2021 Bengü Ergüden; Licensee Cosmos Scholars Publishing House.

This is an open access article licensed under the terms of the Creative Commons Attribution Non-Commercial License (http://creativecommons.org/licenses/by-nc/3.0/), which permits unrestricted, non-commercial use, distribution and reproduction in any medium, provided the work is properly cited. 